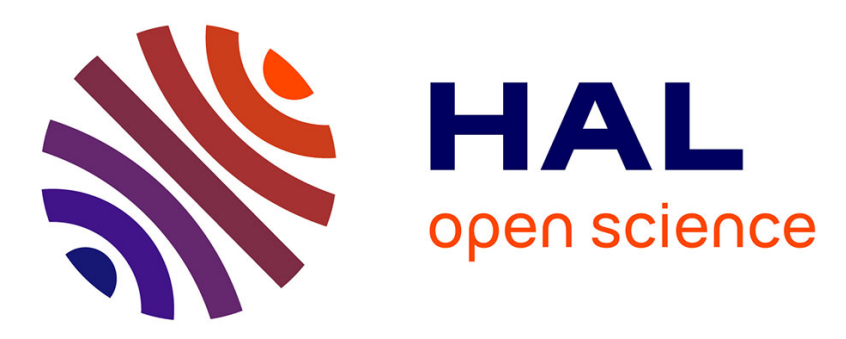

\title{
Multiturn Hollow Helices: Synthesis and Folding of Long Aromatic Oligoamides
}

Yulong Zhong, Brice Kauffmann, Wenwu Xu, Zhong-Lin Lu, Yann Ferrand, Ivan Huc, Xiao Cheng Zeng, Rui Liu, Bing Gong

\section{To cite this version:}

Yulong Zhong, Brice Kauffmann, Wenwu Xu, Zhong-Lin Lu, Yann Ferrand, et al.. Multiturn Hollow Helices: Synthesis and Folding of Long Aromatic Oligoamides. Organic Letters, 2020, 22 (17), pp.69386942. 10.1021/acs.orglett.0c02481 . hal-03007636

\section{HAL Id: hal-03007636 https://hal.science/hal-03007636}

Submitted on 23 Nov 2020

HAL is a multi-disciplinary open access archive for the deposit and dissemination of scientific research documents, whether they are published or not. The documents may come from teaching and research institutions in France or abroad, or from public or private research centers.
L'archive ouverte pluridisciplinaire HAL, est destinée au dépôt et à la diffusion de documents scientifiques de niveau recherche, publiés ou non, émanant des établissements d'enseignement et de recherche français ou étrangers, des laboratoires publics ou privés. 


\title{
Multiturn Hollow Helices: Synthesis and Folding of Long Aromatic Oligoamides
}

\author{
Yulong Zhong, Brice Kauffmann, Wenwu Xu, Zhong-Lin Lu, Yann Ferrand, Ivan Huc, Xiao Cheng Zeng, \\ Rui Liu,* and Bing Gong*
}

\begin{abstract}
Aromatic oligoamides adopting helical conforma- tions are synthesized by coupling carboxyl-terminated basic units having two, four, and eight residues to amine-terminated oligomer precursors. Coupling yields show no noticeable reduction with the size of the basic units or the final product. One- and two- dimensional NMR spectroscopy and computational studies demonstrate the reliable helical folding of these oligomers. The X-ray structure of 16 mer 7 reveals a compact, multiturn helix having a $9 \AA$ inner pore.
\end{abstract}
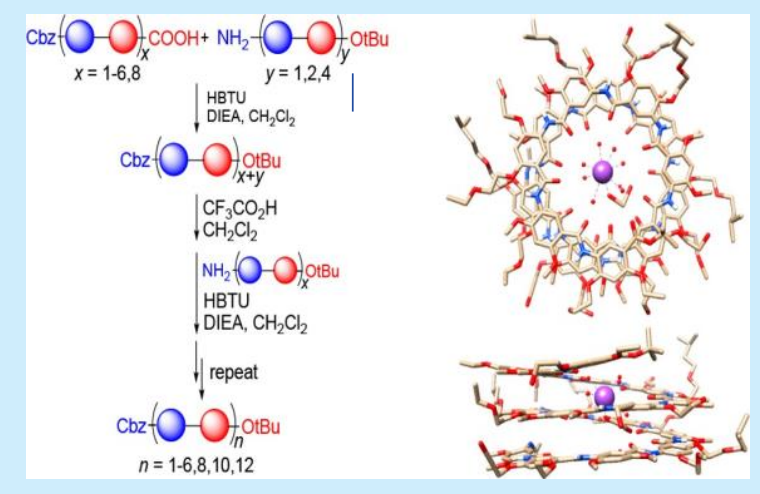

interest he development of foldamers has attracted intense rest for more than two decades. ${ }^{1}$ Among known systems, aromatic oligoamides with restricted conformational freedom represent a major class of foldamers having abiological backbones. ${ }^{2}$ We and others have created aromatic foldamers that adopt stably folded, cavity-containing conformations enforced by highly stable intramolecular hydrogen bonds. ${ }^{3,4}$ General structures A and B (Figure 1) show the first series of oligoamide foldamers we developed. These oligoamides, consisting of meta-linked benzene residues, are forced to fold by localized three-center H-bonds. ${ }^{5}$ Depending on its chain length, an oligoamide folds into either a flat crescent or a helical conformation that contains an inner cavity defined by inward-pointing amide carbonyl oxygens.
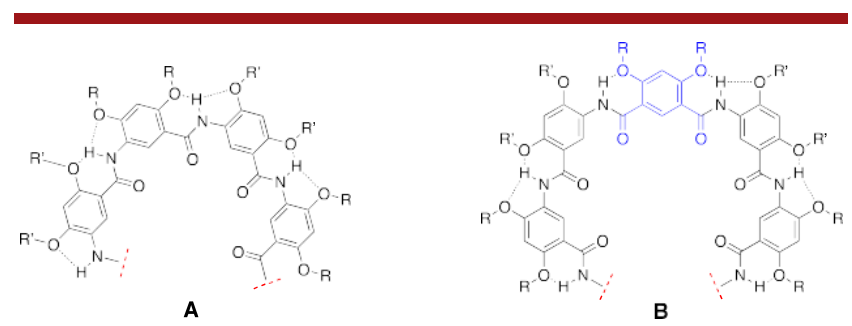

Figure 1. General structures of aromatic oligoamides having (A) an unsymmetrical (N-to-C) backbone and (B) a symmetrical backbone consisting of a central diacid residue (blue) and two identical groups. Hydrogen bonds are shown as dashed lines.

The synthesis of oligoamides A typically involves coupling a monomeric unit carrying an acid chloride and a nitro group to another amine-bearing monomer or oligomer., Reducing the nitro group and coupling with another monomer unit result in chain extension. Repetitive coupling leads to "unsymmetrical" oligoamides A, with up to eight residues.,6 Reacting amineterminated A-type oligomers with a diacid chloride monomer led to "symmetrical" oligoamides B, in fewer coupling steps than the number needed to prepare unsymmetrical oligomers of the same lengths. However, the yields of oligoamide A orB rapidly decrease with an increase in oligomer length, which was believed to be caused by steric hindrance that resulted from the folding of the oligoamides. By temporarily blocking the backbone-constraining three-center $\mathrm{H}$-bonds with an acidlabile 2,4-dimethoxybenzyl (DMB) group, we obtained symmetrical oligoamides with 13 and 15 benzene residues, albeit at the cost of having to take extra steps to modify monomeric and oligomeric precursors. ${ }^{7}$

Reaching longer oligomers is highly desirable. Oligoamides of type A or B with sufficient length will form multiturn helices and may provide "folding nanotubes" that are expected to have novel properties and offer new possibilities. ${ }^{1 e, 2 b}$ Such hollow helices, with their electrostatically negative pores of adjustable depth, may provide hosts that tailor the lengths of guests or serve as ion and molecular channels spanning lipid bilayers. ${ }^{8}$ The availability of such multiturn helices would also address unanswered questions. For example, are the three-center intramolecular H-bonds shown in A or B strong enough to mediate the folding of a long oligoamide into an uninterrupted multiturn helix? The X-ray structure of a type B symmetrical nonamer, the only known crystal structure showing a helical conformation for this series of oligoamides, $3 \mathrm{~b}$ revealed a short (approximately one turn) helix having a pitch of $\sim 7.1 \AA$, which indicates the absence of aromatic stacking within this helix. If a multiturn helix does form, is the helix compact or extended? How many residues constitute one turn in such a helix? 
Herein, we report the synthesis of type A oligoamides by coupling differently sized building blocks to a growing amineterminated oligoamide chain. Oligoamides with $\leq 24$ residues are obtained. The synthesized oligoamides were examined with one-dimensional (1D) NMR spectroscopy, which revealed upfield shifts of aromatic proton resonances that indicate the involvement of intramolecular stacking in the folding of these oligomers. The folded structures were computationally optimized, which provided helices of different lengths. These oligoamides were analyzed with two-dimensional (2D) (ROESY or NOESY) NMR spectroscopy; the results are consistent with the presence of helical conformations. In addition, single crystals of a 16-residue oligomer were obtained and led to the determination of the first crystal structure of a multiturn helix for this series of aromatic oligoamides.

Scheme 1. Synthetic Routes of Aromatic Oligoamides

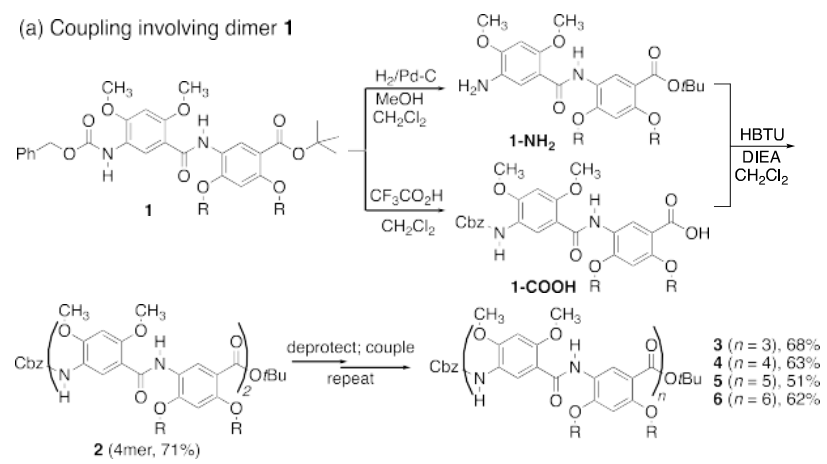

(b) Coupling involving tetramer 2

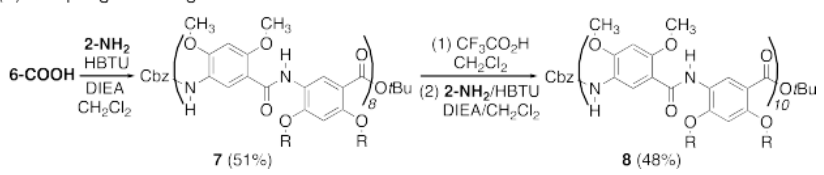

(c) Coupling involving octamer 4

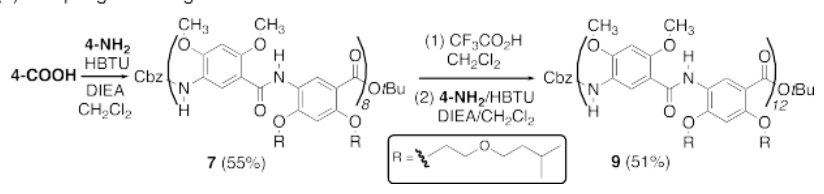

Scheme 1 shows the synthetic routes for preparing tetramer 2 through 24mer 9. Coupling steps are based on building blocks derived from dimer 1 (Supporting Information), which bears the orthogonal protecting carboxybenzyl $(\mathrm{Cbz})$ and tertbutyl groups at its $\mathrm{N}$ - and C-termini, respectively (Scheme 1a). Reacting acid $1-\mathrm{COOH}$ and amine $1-\mathrm{NH}_{2}$, obtained by removing the $\mathrm{Cbz}$ and tert-butyl groups of dimer 1, respectively, in the presence of the coupling reagent HBTU and $\mathrm{N}, \mathrm{N}$-diisopropylethylamine (DIEA) in $\mathrm{CH}_{2} \mathrm{Cl}_{2}$ for at least $12 \mathrm{~h}$ afforded tetramer 2 that bears an $\mathrm{N}-\mathrm{Cbz}$ and a tert-butyl ester group. Removing the tert-butyl group of 2 gives the
Scheme $1 \mathrm{~b}$ shows chain extension using the four-residue 2$\mathrm{NH}_{2}$ derived from tetramer 2. Reacting the 12-residue acid 6$\mathrm{COOH}$ with $2-\mathrm{NH}_{2}$ gave 16 mer 7 in $51 \%$ yield. Coupling 16residue acid $7-\mathrm{COOH}$ with four-residue amine $2-\mathrm{NH}_{2}$ gave 20 mer 8 in $48 \%$ yield. As shown in Scheme 1c, coupling building blocks 4-COOH and 4- $\mathrm{NH}_{2}$, derived from octamer 4 by removing the $\mathrm{Cbz}$ and tert-butyl groups, respectively, led to 16 mer 7 in $55 \%$ yield after extensive purification. Removing the tert-butyl group of 16 mer 7 gave the carboxyl-terminated 7$\mathrm{COOH}$, which was then coupled with eight-residue amine 4$\mathrm{NH}_{2}$ to give 24 mer 9 in $51 \%$ yield after extensive purification. The yields of the isolated oligoamides from coupling fourresidue amine $2-\mathrm{NH}_{2}$ and eight-residue amine $4-\mathrm{NH}_{2}$ show no noticeable difference. In fact, the yields of the coupling reactions involving the two-, four-, and eight-residue amines 1$\mathrm{NH}_{2}, 2-\mathrm{NH}_{2}$, and 4-NH , respectively, do not show a correlation with the size of the basic coupling units. Under the adopted conditions, the final products, i.e., oligoamides with 4-24 residues, were prepared in satisfactory yields, suggesting that our synthetic method is suitable for preparing even longer oligoamides. In a recently published work on the synthesis of a different series of aromatic oligoamides, ${ }^{9}$ Huc et al. concluded that coupling of long sequences is slower but does not stop the coupling. An increasing reaction times helps, and an increasing concentration is critical.

Oligoamides 4-9 were fully optimized using a density functional theory (DFT) method implemented in the CP2K package (see the Supporting Information). The optimized structures reveal structural parameters, including $\sim 6.3$ residues per helical turn, ${ }^{10}$ a diameter of $\sim 8.3 \AA(\mathrm{O}-\mathrm{O})$ for the inner cavity, and a helical pitch of $\sim 3.5 \AA$ indicating that the helical structures are stabilized by effective aromatic stacking involving the benzene residues and amide groups of adjacent turns (Figure S1).

The ${ }^{1} \mathrm{H}$ NMR spectra of oligoamides 4-9 (Figure S2) have three distinct regions, i.e., from 9.62-10.30, 8.68-9.30, and 6.24-6.86 ppm, which show the signals of the backbone amide protons, the "internal" aromatic protons, i.e., those placed inside the cavities, and the "external" aromatic protons flanked by the phenolic ether side chains. The overall sharpness and wide resonance dispersion of the amide and aromatic signals are consistent with the well-defined conformations adopted by these oligomers. ${ }^{3 c}$

The average chemical shift of the aromatic protons of hexamer 3 through 24 mer 9 was determined by dividing the sum of the chemical shift values of these protons with the total number of such hydrogens in each oligomer. The aromatic proton signals exhibit an upfield shift with an increase in oligomer length (Figure 2), indicating stacking of the aromatic residues due to the adoption of helical conformations. ${ }^{11}$ From hexamer 3 to decamer 5 , which adopt conformations with 


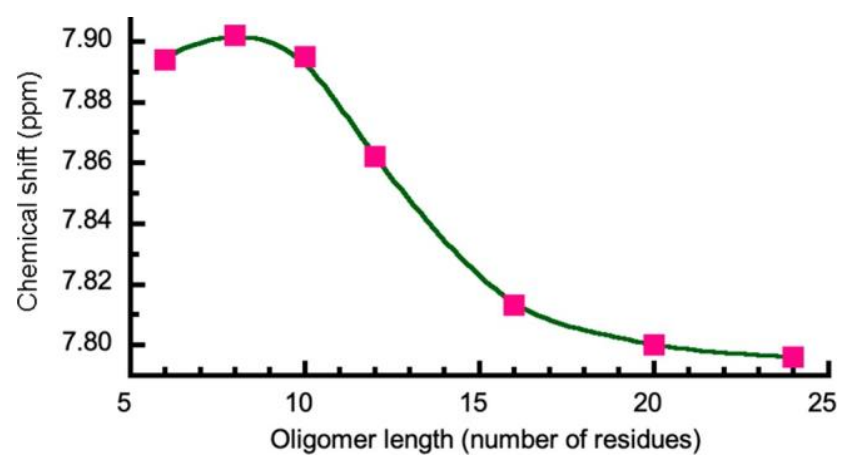

Figure 2. Average chemical shifts of aromatic protons vs chain length for hexamer 3 through $24 \mathrm{mer} 9(1 \mathrm{mM})$. The ${ }^{1} \mathrm{H}$ NMR spectra were recorded in DMSO- $d_{6} / \mathrm{CDCl}_{3}[1 / 1(\mathrm{v} / \mathrm{v})]$ at $45^{\circ} \mathrm{C}$.

fewer than one turn to $\sim 1.5$ turns, the average chemical shift of the aromatic protons exhibits a negligible upfield shift. From decamer 5 to 24 mer 9 , the average chemical shift of aromatic proton resonances shows a noticeable upfield shift, from 7.90 to $7.80 \mathrm{ppm}$. This indicates that, with an increase in chain length, aromatic stacking is enhanced by the adoption of helical conformations. The fact that the upfield shift of the aromatic proton resonances continues as oligomer length extends implies that the intramolecular aromatic stacking may be cooperative; i.e., such an interaction is strengthened as the number of aromatic units, i.e., the number of helical turns, increases. Thus, a longer oligoamide that folds into multiple turns experiences stronger interturn aromatic stacking than a shorter one does.

The ROESY spectrum of octamer 4 and NOESY spectra of 12 mer 6, 16mer 7, and 20 mer 8 were recorded (Figure S3). One $\mathrm{ROE}$ is detected between protons b2 and d of 4 (Figure S3a), which is consistent with the folding of 4 into a helical conformation that brings these remote protons into the proximity of each other.

A large number of NOE contacts consistent with the helical folding of 6 (Figure S3b), 7 (Figure S3c), and 8 (Figure 3 and Figure S3d) are found. Major NOEs revealed with 20 mer 8 are between protons $\mathrm{a} 1$ and b8, a 9 and b2, a10 and b17, a11 and

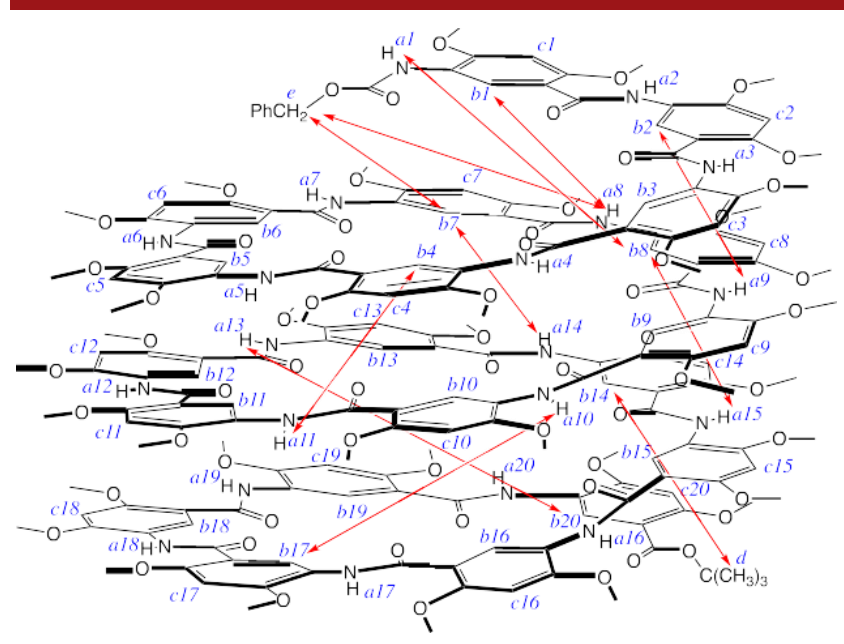

Figure 3. Conformation of 20 mer 8 drawn based on energyminimized helical structure, supported by NOEs (red arrows) revealed by the NOESY spectrum of 8 . The numbering of amide and aromatic hydrogen atoms starts from the $\mathrm{N}$-terminus of each oligomer. Side chains are shown as methyl groups. b4, a13 and b20, a14 and b7, and a15 and b8 (Figure 3). The observed NOEs involve protons on residues that are six and seven basic units apart, while no NOE between protons on residues that are inside or beyond this range is detected, indicating that the two groups of protons being placed in the proximity of each other belong to adjacent turns of a helix. Thus, the number of residues per helical turn is between six and seven turns, consistent with the computationally revealed $\sim 6.3$ residues per turn.

Single crystals of 16 mer 7 were obtained by slow liquidliquid diffusion of a solution of 7 in chloroform into methanol. As shown in Figure 4, the crystal structure of 7 reveals a well-

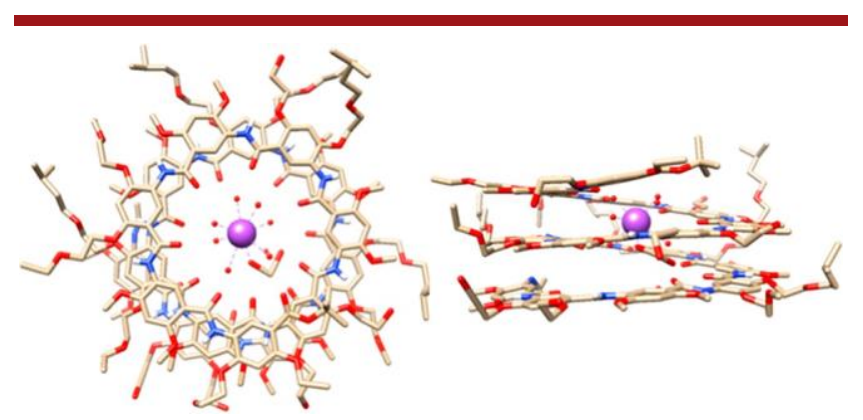

Figure 4. Top and side views of the crystal structure of 16 mer 7 . Hydrogen atoms, other than those of the amide groups, along with $\mathrm{PF}_{6}-$ ions have been omitted for the sake of clarity.

defined helix, in which some of the side chains and the $\mathrm{Cbz}$ protecting group are disordered. With $\sim 6.6$ residues per turn, oligomer 7 folds into a helix of $\sim 2.5$ turns. The helical pitch of $\sim 3.4 \AA$ indicates that the aromatic residues engage in strong intramolecular aromatic stacking interaction, which results in a compact helix. The inner cavity of this helix, defined by 16 centripetally pointed carbonyl oxygens, has a diameter of $9.0 \AA$. Interestingly, a $\mathrm{Na}^{+}$ion is complexed in the cavity, with water and methanol molecules serving as the first sphere of coordination, and the inward-pointing oxygen atoms as the second sphere. ${ }^{12}$ This hints at possible binding of guests having multiple hydrogen bond donors.

In summary, type A oligoamides with lengths of $\leq 24$ residues have been synthesized. Coupling differently sized building blocks to a growing oligomer chain gives oligoamides of the desired length in satisfactory yields. The synthesized oligoamides were examined with NMR spectroscopy, along with computational studies, which demonstrated the helical folding of these molecules. The X-ray structure of $16 \mathrm{mer} 7$ reveals a compact helix of $\sim 2.5$ turns with structural parameters, including the helical pitch, number of residues per turn, and diameter of the inner pore, based on which the folded structures of other oligomers of this series can be accurately modeled. This study has not only demonstrated the reliable folding of these oligoamides but also, for the first time, confirmed that the longer oligomers of this series fold into multiturn helices that are stable and compact and contain large hydrophilic inner pores.

\section{ASSOCIATED CONTENT}

The Supporting Information is available free of charge at https://pubs.acs.org/doi/10.1021/acs.orglett.0c02481. 
Supporting figures, experimental details, 1D and 2D NMR spectra, MS spectra, and computational methods (PDF)

Accession Codes

CCDC 1971430 contains the supplementary crystallographic data for this paper. These data can be obtained free of charge via www.ccdc.cam.ac.uk/data_request/cif, or by emailing data_request@ccdc.cam.ac.uk, or by contacting The Cambridge Crystallographic Data Centre, 12 Union Road, Cambridge CB2 1EZ, UK; fax: +44 1223336033.

\section{AUTHOR INFORMATION}

Corresponding Authors

Bing Gong - Department of Chemistry, University at Buff alo, the State University of New York, Buff alo, New York 14260, United States; orcid.org/0000-0002-4155-9965;

Email: bgong@buff alo.edu

Rui Liu - College of Chemistry, Beijing Normal University, Beijing 100875, China; Email: 11112016094@bnu.edu.cn

Authors

Yulong Zhong - Department of Chemistry, University at Buff alo, the State University of New York, Buff alo, New York 14260, United States

Brice Kau $\square$ mann - Institut Europeén de Chimie et Biologie,

UMS3011/US001 CNRS, Inserm, Universitéde Bordeaux, F- 33600 Pessac, France; $\quad$ orcid.org/0000-0002-2932-3255

Wenwu Xu - Department of Chemistry, University of Nebraska Lincoln, Lincoln, Nebraska 68588, United States;

orcid.org/0000-0002-0651-9562

Zhong-Lin Lu - College of Chemistry, Beijing Normal University, Beijing 100875, China; orcid.org/0000-0001- 5473-2889

Yann Ferrand - Institut de Chimie et Biologie des Membranes et des Nanoobjets, UMR 5248 CNRS, Universitéde Bordeaux, F-

33600 Pessac, France; orcid.org/0000-0002-6552-6914

Ivan Huc - Department Pharmazie, Ludwig-Maximilians-

UniversitatMünchen, D-81377 Munich, Germany;

orcid.org/0000-0001-7036-9696

Xiao Cheng Zeng - Department of Chemistry, University of Nebraska

Lincoln, Lincoln, Nebraska 68588, United States;

orcid.org/0000-0003-4672-8585

Complete contact information is available at:

https://pubs.acs.org/10.1021/acs.orglett.0c02481

Notes

The authors declare no competing financial interest.

\section{ACKNOWLEDGMENTS}

This work was supported by the National Science Foundation (Grant CHE-1905094 to B.G. and X.C.Z.).

\section{REFERENCES}

(1) (a) Seebach, D.; Matthews, J. L. $\beta$-Peptides: a surprise at every turn. Chem. Commun. 1997, 2015. (b) Gellman, S. H. Foldamers: a manifesto. Acc. Chem. Res. 1998, 31, 173. (c) Hill, D. J.; Mio, M. J.; Prince, R. B.; Hughes, T. S.; Moore, J. S. A field guide to foldamers. Chem. Rev. 2001, 101, 3893. (d) Cubberley, M. S.; Iverson, B. L. Models of higher-order structure: foldamers and beyond. Curr. Opin. Chem. Biol. 2001, 5, 650. (e) Gong, B. Crescent oligoamides: from acyclic "macrocycles" to folding nanotubes. Chem. - Eur. J. 2001, 7, 4336. (f) Goodman, C. M.; Choi, S.; Shandler, S.; DeGrado, W. F.
Foldamers as versatile frameworks for the design and evolution of function. Nat. Chem. Biol. 2007, 3, 252. (g) Martinek, T. A.; Fulöp, F. Peptidic foldamers: ramping up diversity. Chem. Soc. Rev. 2012, 41, 687. (h) Spencer, R.; Chen, K. H.; Manuel, G.; Nowick, J. S. Recipe for $\beta$ sheets: foldamers containing amyloidogenic peptide sequences. Eur. J. Org. Chem. 2013, 2013, 3523. (i) Hartley, C. S. Folding of orthophenylenes. Acc. Chem. Res. 2016, 49, 646. (j) Le Bailly, B.; Clayden, J. Dynamic foldamer chemistry. Chem. Commun. 2016, 52, 4852. (k) John, E. A.; Massena, C. J.; Berryman, O. B. Helical anion foldamers in solution. Chem. Rev. 2020, 120, 2759.

(2) (a) Huc, I. Aromatic oligoamide foldamers. Eur. J. Org. Chem. 2004, 17-29. (b) Gong, B. Hollow crescents, helices and macrocycles from enforced folding and folding-assisted macrocyclization. Acc. Chem. Res. 2008, 41, 1376. (c) Saraogi, I.; Hamilton, A. D. Recent advances in the development of aryl-based foldamers. Chem. Soc. Rev. 2009, 38, 1726. (d) Zhang, D. W.; Zhao, X.; Hou, J. L.; Li, Z. T. Aromatic amide foldamers: structures, properties, and functions.

Chem. Rev. 2012, 112, 5271.

(3) (a) Zhu, J.; Parra, R. D.; Zeng, H.; Skrzypczak-Jankun, E.; Zeng, X. C.; Gong, B. A new class of folding oligomers: crescent oligoamides. J. Am. Chem. Soc. 2000, 122, 4219. (b) Gong, B.; Zeng, H. Q.; Zhu, J.; Yua, L. H.; Han, Y. H.; Cheng, S. Z.; Furukawa, M.; Parra, R. D.; Kovalevsky, A. Y.; Mills, J. L.; Skrzypczak-Jankun, E.; Martinovic, S.; Smith, R. D.; Zheng, C.; Szyperski, T.; Zeng, X. C. Creating nanocavities of tunable sizes: hollow helices. Proc. Natl. Acad. Sci. U. S. A. 2002, 99, 11583-11588. (c) Yuan, L.; Zeng, H.; Yamato, K.; Sanford, A. R.; Feng, W.; Atreya, H. S.; Sukumaran, D. K.; Szyperski, T.; Gong, B. Helical aromatic oligoamides: reliable, readily predictable folding from the combination of rigidified structural motifs. J. Am. Chem. Soc. 2004, 126, 16528. (d) Hu, T.; Connor, A. L.; Miller, D. P.; Wang, X.; Pei, Q.; Liu, R.; He, L.; Zheng, C.; Zurek, E.; Lu, Z. L.; Gong, B. Helical folding of meta-connected aromatic oligoureas. Org. Lett. 2017, 19, 2666. (e) Zhao, Y. Y.; Connor, A. L.; Sobiech, T. A.; Gong, B. Effects of oligomer length, solvents, and temperature on the self-association of aromatic oligoamide foldamers. Org. Lett. 2018, 20, 5486.

(4) (a) Hamuro, Y.; Geib, S. J.; Hamilton, A. D. Novel folding patterns in a family of oligoanthranilamides: non-peptide oligomers that form extended helical secondary structures. J. Am. Chem. Soc. 1997, 119, 10587. (b) Berl, V.; Khoury, R. G.; Huc, I.; Krische, M. J.; Lehn, J.-M. Interconversion of single and double helices formed from synthetic molecular strands. Nature 2000, 407, 720. (c) Hou, J. L.; Shao, X. B.; Chen, G. J.; Zhou, Y. X.; Jiang, X. K.; Li, Z. T. Hydrogen bonded oligohydrazide foldamers and their recognition for saccharides. J. Am. Chem. Soc. 2004, 126, 12386. (d) Dolain, C.; Jiang, H.; Leger, J. M.; Guionneau, P.; Huc, I. Chiral induction in quinolinederived oligoamide foldamers: assignment of helical handedness and role of steric effects. J. Am. Chem. Soc. 2005, 127, 12943. (e) Yan, Y.; Qin, B.; Shu, Y. L.; Chen, X. Y.; Yip, Y. K.; Zhang, D. W.; Su, H. B.; Zeng, H. Q. Helical organization in foldable aromatic oligoamides by a continuous hydrogen-bonding network. Org. Lett. 2009, 11, 1201.

(f) Burslem, G. M.; Kyle, H. F.; Prabhakaran, P.; Breeze, A. L.; Edwards, T. A.; Nelson, A. S.; Warriner, S. L.; Wilson, A. J. Synthesis of highly functionalized oligobenzamide proteomimetic foldamers by late stage introduction of sensitive groups. Org. Biomol. Chem. 2016, 14, 3782. (g) Meisel, J. W.; Hu, C. H. T.; Hamilton, A. D. Mimicry of a $\beta$ hairpin turn by a nonpeptidic laterally flexible foldamer. Org. Lett. 2018, 20, 3879. (h) Urushibara, K.; Ferrand, Y.; Liu, Z. W.; Masu, H.; Pophristic, V.; Tanatani, A.; Huc, I. Frustrated helicity: joining the diverging ends of a stable aromatic amide helix to form a fluxional macrocycle. Angew. Chem., Int. Ed. 2018, 57, 7888. (i) Liu, C. Z.; Koppireddi, S.; Wang, H.; Zhang, D. W.; Li, Z. T. Halogen bonding directed supramolecular quadruple and double helices from hydrogenbonded arylamide foldamers. Angew. Chem., Int. Ed. 2019, 58, 226.

(5) Parra, R. D.; Zeng, H. Q.; Zhu, J.; Zheng, C.; Zeng, X. C.; Gong, B. Stable three-center hydrogen bonding in a partially rigidified structure. Chem. - Eur. J. 2001, 7, 4352. 
(6) Yuan, L.; Sanford, A. R.; Feng, W.; Zhang, A.; Zhu, J.; Zeng, H.; Yamato, K.; Li, M.; Ferguson, J. S.; Gong, B. Synthesis of crescent aromatic oligoamides. J. Org. Chem. 2005, 70, 10660.

(7) Zhang, A. M.; Ferguson, J. S.; Yamato, K.; Zheng, C.; Gong, B. Improving foldamer synthesis through protecting group induced unfolding of aromatic oligoamides. Org. Lett. 2006, 8, 5117.

(8) Gong, B.; Shao, Z. F. Self-assembling organic nanotubes with precisely defined, sub-nanometer pores: formation and mass transport characteristics. Acc. Chem. Res. 2013, 46, 2856.

(9) Li, X. S.; Qi, T.; Srinivas, K.; Massip, S.; Maurizot, V.; Huc, I. Synthesis and multibromination of nanosized helical aromatic amide foldamers via segment-doubling condensation. Org. Lett. 2016, 18, 1044.

(10) An earlier computation revealed 6.5 residues per turn: $\mathrm{Fu}, \mathrm{H}$. L.; Liu, Y.; Zeng, H. Q. Shape-persistent H-bonded macrocyclic aromatic pentamers. Chem. Commun. 2013, 49, 4127.

(11) (a) Nelson, J. C.; Saven, J. G.; Moore, J. S.; Wolynes, P. G. Solvophobically driven folding of nonbiological oligomers. Science 1997, 277, 1793. (b) Kim, U. I.; Suk, J. M.; Naidu, V. R.; Jeong, K. S. Folding and anion-binding properties of fluorescent oligoindole foldamers. Chem. - Eur. J. 2008, 14, 11406. (c) Delsuc, N.; Kawanami, T.; Lefeuvre, J.; Shundo, A.; Ihara, H.; Takafuji, M.; Huc, I. Kinetics of helix-handedness inversion: folding and unfolding in aromatic amide oligomers. ChemPhysChem 2008, 9, 1882.

(12) Mateus, P.; Wicher, B.; Ferrand, Y.; Huc, I. Chem. Commun. 2017, 53, 9300 . 